\title{
Blue-collar workplace communicative practices: a case study in construction sites in Qatar
}

\author{
Irene Theodoropoulou ${ }^{1}$
}

Received: 1 September 2017 / Accepted: 22 January 2019 / Published online: 13 April 2019

(c) The Author(s) 2019

\begin{abstract}
The aim of this paper is to contribute to the understanding of the role of language in multilingual blue-collar workplaces by investigating how communication is realized in construction sites in Qatar. The State of Qatar offers a unique and, hence, very interesting setting for the linguistic investigation of migration-related issues, such as multilingualism (Pietikäinen et al. in Sociolinguistics from the periphery: small languages in new circumstances, Cambridge University Press, Cambridge, 2016), due to the fact that over $90 \%$ of its population consists of non-citizens (Ahmad, in: Kamrava, Babar (eds) Migrant labor in the Persian Gulf, Hurst \& Company, London, pp 21-40, 2015). In addition, after its successful bid to host the World Cup 2022, the country is currently witnessing a rapid transformation of its landscape evident through its massive number of construction sites, where people of different national, ethnic and social class backgrounds from all over the world are hired to work together in developing the infrastructure that is part of the ambitious Qatar Vision 2030. Against this backdrop, the focus is on the sociolinguistic resources (Blommaert in The sociolinguistics of globalization, Cambridge University Press, Cambridge, 2010) mobilized in a construction site at a university in Qatar. The multilingual community of practice (Lave and Wenger in Situated learning: legitimate peripheral participation, Cambridge University Press, New York, 1991) investigated consists of blue-collar workers from India and their communication practices with their supervisors, who are project site engineers from all over the world. In such transnational fields, where effective communication is a sine qua non not only for the successful completion of the project or infrastructure itself but also, and perhaps most importantly, for the safety of everybody involved in the construction, multilingualism is the norm. It is argued that communication is realized through spatial repertoires (Canagarajah, in: Canagarajah (ed) The Routledge handbook of migration and language, Routledge, New York, pp 1-28, 2017), that are constructed and used as ingroup markers to facilitate communication among people from different nationalities, ethnicities and social classes. The ethnographic data, collected for almost 13 months, comprise voice-recorded interactions, field notes from on-site participant observation as well as ethnographic interviews with select blue-collar workers and
\end{abstract}

Extended author information available on the last page of the article 
their supervisors. The linguistic and exolinguistic analysis is contextualized in the broader socio-political and economic forces of Qatar (Fromherz in Qatar. A modern history, Georgetown University Press, Washington, 2012; Kamrava in Qatar: small state, big politics, Cornell University Press, Ithaca, 2015; chapters in Kamrava and Babar in Migrant labor in the Persian Gulf, Hurst \& Company, London, 2015).

Keywords Qatar · Blue-collar workplace · Spatial repertoire · Ethnography · Sociolinguistic scale

\section{Introduction}

One of the recent developments in sociolinguistic scholarship is a shift towards a more dynamic approach to the relationship between language and society, which essentially has created a strand tentatively labelled the "sociolinguistics of mobility" (Blommaert 2014; Blommaert et al. 2017; Pennycook 2012; Theodoropoulou 2015), where language is considered "unbound" (Canagarajah 2017: 7). What is meant by this is that an analytical effort is made to understand the flows across time and space of linguistic and semiotic resources "unfettered from an imposed structure" (ibid.)

As an ongoing and fleeting activity, communication has been investigated through a range of useful analytical tools, such as "translanguaging" (Garcia 2009; Baker 2011; Blackledge and Creese 2017), "translingual practices" (Canagarajah 2013) or "sociolinguistic repertoires" (Blommaert 2010, 2013a, b) or "communicative repertoires" (Rymes 2014) in superdiversity (Blommaert and Backus 2013). The basic idea underlying all these concepts is that language is understood as a diverse set of verbal (e.g. words, intonational contours, interactional strategies, fixed expressions), semiotic (e.g. body posture, facial expressions, clothing, among others) and sociocultural resources (e.g. images, emoticons and other artifacts) that people know by degree and can use to enhance their linguistic input/output. These features also include more interaction-oriented moves, such as (im)politeness patterns as well as phatic communication (e.g. small talk). Such an approach is practice-based (de Certeau 1984) and the norms and meanings that are shaped in the context of this communication are created by an assemblage of diverse resources.

Moving away from a focus on national, official, "top-down" policy, there is an increasing emphasis on analyzing local agency and resistance as these official documents are implemented in social practice (cf. Hassa 2012). While there is a growing body of research on the local processes of policy implementation, there has been scant work on how these localized social practices can also in turn impact and even become official policy (for an overview, see Hornberger et al. 2018: 161-165).

With respect to the analysis of blue-collar workplace communicative practices, I am using the concept of "spatial repertoires" (Pennycook and Otsuji 2014, 2015: Chapter 4, 2017), which includes diverse semiotic resources, defined by and embedded in the space/time contingencies of communication. In order for a speaker to be considered as competent in spatial repertoires what matters is not the knowledge of the grammatical structure of specific languages (e.g. Tamil and Malayalam), but 
they must know "how words align with objects, people and contexts to be meaningful" (Canagarajah 2017: 9)

Apart from spatial repertoires, I am also using a relevant notion which is that of "spatiotemporal scales" (Blommaert 2007; Prinsloo 2017) and scalar theory; from the perspective of scales, these spatial repertoires operate in specific social and spatial domains, in the sense that they are layered and stratified. What counts as an appropriate repertoire is a situated, placed or localized judgment. The structural or systemic impetus for scale-setting is an effect of global capitalism operating as a world system.

Given that both these are recent concepts in the sociolinguistics of mobility, I use these terms as heuristics to analyze my collected blue-collar labor interactions, namely the exchange of utterances between blue-collar workers and their supervisors in the construction site aiming at a smooth and efficient communication (cf. Jørgensen 2008). The latter translates into the achievement of tangible results that make the work move forward (e.g. the completion of successfully putting bricks together to build a wall). The basic argument put forward is that spatial repertoires and spatiotemporal scales are used as in-group communicative repertoires in the construction site for meaning-making in workplace communication, which essentially translates into their survival and consequent attempt to run a decent life in Qatar and to also be able to send remittances to their families back in their respective countries.

Against this theoretical backdrop, this paper is concerned with communication processes, where language and nonverbal resources are used to (re-)create spatial repertoires, in the under-researched multilingual blue-collar workplace in Qatar (although see chapters in Kamrava and Babar 2015), and the relationship between policy and practice. More specifically, the research questions addressed include the role of language and semiosis in the communicative patterns of blue-collar workplaces, as well as the ways bottom up communicative practices interact (or not) with prescribed language policies in Qatari blue-collar workplaces. Before this discussion, however, a description of the methodology I used to collect my blue-collar labor data is in order.

\section{Methodology and data}

My encounter with blue-collar workers in Qatar started officially in September 2010 in my workplace and residence area in Doha, the capital of Qatar, where a number of security guards, cleaners, plumbers, and gardeners primarily from the Indian subcontinent and, secondarily, from the Philippines, are to be found. These are unskilled workers, namely people who have received less training than semi-skilled workers or, having not received any training, they have still acquired their competence on the job (Vigouroux 2017: 315; Lønsmann and Kraft 2017: 138-139). Of course, there is immense variation in terms of skills of these people, in the sense that some of them in their countries of origin are considered to be skilled, because they have received some training and/or have even graduated from university. However, the participants of focus here are all unskilled labor of Indian origin. They have been recruited by agencies in India, which send workers to the Gulf countries, including Qatar (cf. 
Breeding 2015). Unskilled Indians in the construction sector form $70 \%$ of the group and the rest are divided between medium level professionals (people having received vocational training and acting as team supervisors) as well as highly skilled categories that are here termed as "white-collar" occupations.

In order to identify the communicative patterns and their linguistic and semiotic realization in blue-collar workplaces, I used "enhanced ethnography" (cf. Wilce 2009: 3-4). Such ethnography incorporates history, reflexivity, and performance in narratives about personal life trajectories of professional expats and unskilled labor from India. All these sources have been used in the analysis. Ethnography focuses on situations as they unfold naturally. This naturalness begs for ethnography being "inherently multi-methodological in focus" (Flick 2004: 226-227), including, among others, "multiple interactive and humanistic methods primarily known as interviewing, observing, gathering documents, and examining material culture" (Rossman and Rallis 2003: 9). As such, ethnography can complexify, rather than simplify, social experiences and meanings, constituting a counter-hegemonic paradigm "that destabilizes accepted views by allowing different voices to speak: a science that constantly calls into question the status of "truth"" (Blommaert 2009: 258). In this sense, my ethnographic take of language policy (cf. Hornberger and Cassells Johnson 2011) is also a critical one, inasmuch as it allows me to observe how top down language policies and bottom-up communicative practices interact, "constantly configuring and being (re)configured within a larger sociocultural landscape, which they in turn (re)shape" (McCarty 2011: 17).

In light of this, I officially started following ethnographically the lives of 10 male workers ( 2 white-collar engineers, 2 site engineers, who were also team supervisors and their role was very important, as they were acting as intermediaries between the white-collar engineers and the blue-collar workers in terms of communication, and finally, 6 blue-collar workers) in October 2013 until November 2014 in the context of a funded research project on identity construction in Qatar. The participants' demographic specifics can be found in Table 1. I used to observe these participants in their activities and verbal practices without interacting with them extensively, but with some minor phatic communication, in which I always feel obliged to engage in out of courtesy to my interlocutors. An emerging ethnographic pattern I have noticed since I came to Qatar is that many blue-collar workers from the Indian subcontinent tend to refrain from initiating interactions with Westerners, but when they are addressed by the latter (e.g. in the case of road instructions), they always make an effort to respond (usually via gestures) and help them and, when they do not know or cannot communicate whatsoever, they always seek for help among the group. Some of these people have also been observed nodding their head moving it sideways to express their promise that they will do something or their need to calm you down and the assertion that everything will be ok.

My ethnographic participant observation of all participants was completed in November 2014, as 9 of these individuals had their contracts terminated then, so they had to leave the country. It is worth mentioning that these people were working in various construction sites and various areas in and around a university campus in Qatar, they belonged to different companies and they came from various areas of India. All of them were aged between 20 and 53 years old. I observed all of them in 


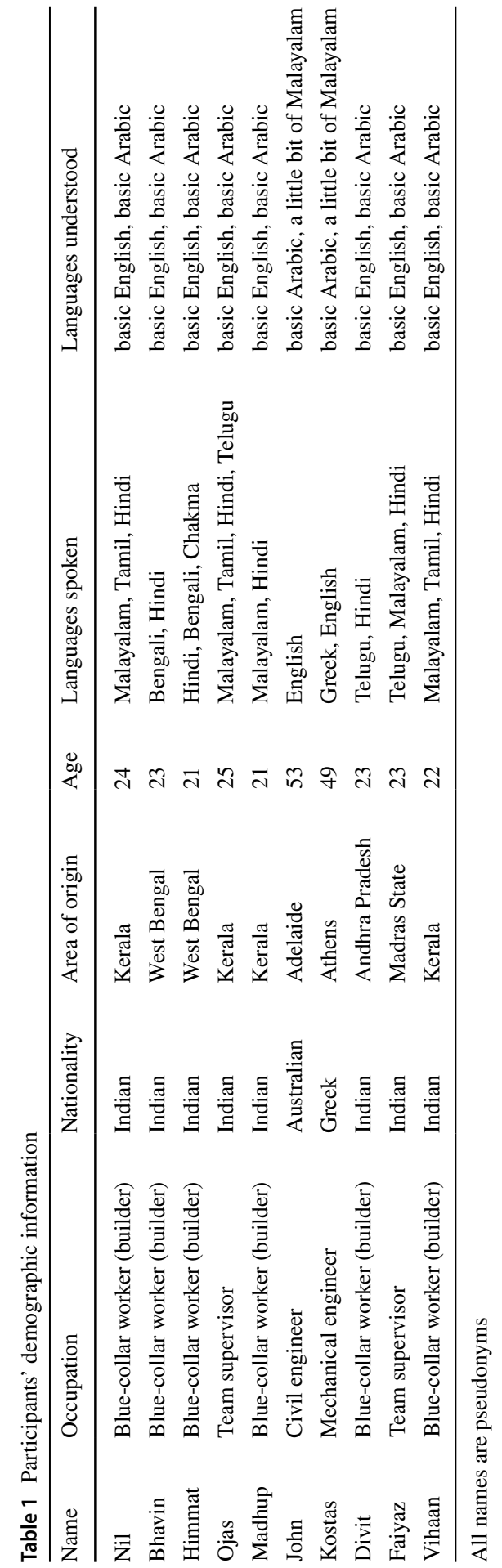


their workplace only, and I took notes. In addition, I asked John and Kostas, the two engineers to whom I had access as a professional Western female, to voice-record random interactions they had with the team supervisors and the team members (subject to the latter two groups' agreement, of course) in a quiet place, ${ }^{1}$ and then I held some play back sessions with them, in which I asked them questions about the context of these recorded interactions. To secure accuracy, the data in Malayalam, Hindi, Bengali and Telugu were transcribed and translated in English by two research assistants, who are native speakers of these languages.

In Qatar, in addition to all countries in the Gulf, Indians are generally organized around region and language-based affiliations (Vora 2013). Malayalees (from Kerala) and Telugus (from Andhra Pradesh) are the dominant groups followed by Punjabi and Tamil communities in Doha. Arang is one of the Kerala associations that shows a broader range of activity and mass in membership (e.g. playing cricket every Friday, hanging out in the area outside the Museum of Islamic Art at the Corniche on Fridays and, sometimes on Sundays, among other activities) compared to the Telugu one that was found to be more of an inner-group with activity largely limited to social get-togethers and entertainment (primarily going to the movies inside Industrial city at the outskirts of Doha). One "All-India" grouping, Bharathi, celebrates programs with a larger scope and national events/festivals (e.g. the celebration of Independence day, Deepavali, which is a major Hindu festival of lights celebrated every year in autumn, or for other specific causes). However, the communicative patterns these diverse Indian groups employ in their workplace have not been investigated, hence this paper deals with them and it discusses them against the backdrop of wider sociopolitical discourses pertaining to the Indian presence in Qatar. In order to understand these patterns, though, a brief historical contextualization of policies pertaining to the bilateral relationship between India and Qatar is provided below.

\section{India and the State of Qatar: some historical policy-related insights}

India and the Gulf have developed a mutually convenient and financially beneficial relationship with each other over the years due to trade migration (cf. Han 2017). Prior to the arrival of Portuguese and then the British, pearling was the main industry in the Gulf. Many families spent months apart during the pearl-diving season, and divers lived in a cycle of constant debt, diving to pay off money owed from the previous season. Under these circumstances, Indians and Iranian merchants, who traded pearls, dates, and other Gulf items from Bombay and other coastal cities around the Indian Ocean, had branches in the Gulf and often lent money to the divers and pearling ship owners. Hence, Indians were sometimes seen as exploitative. All the same, India was also seen as a cultural center for people in the Gulf, which essentially meant that people traveled to India when

\footnotetext{
1 See Lønsmann and Kraft (2017) for a discussion of the challenges collecting data in blue-collar workplaces.
} 
they could, Indian goods were coveted items, and Hindi and Urdu were widely spoken. These long standing networks of trade and communication became formalized and entrenched through the Trucial Agreements imposed by the British government on Gulf sheikhs. Qatar, for the Indians who belong to my sample of participants, is both a site of material possibility and a place that holds a certain affective, historical and cultural position within a transnational understanding (cf. Allan and McElhinny 2017; Lorente 2017; Theodoropoulou and Alos 2018; Theodoropoulou forthcoming) of Indianness. From a transnational perspective (Lorente 2017), the historical and contemporary role of migration and cosmopolitanism has started being incorporated into the sociocultural and sociolinguistic analysis of the Gulf (cf. Fromherz 2012; Kamrava 2015).

Industrial city, which is a cluster of neighborhoods playing host to labor from the Indian sub-continent, is geographically segregated from older and newer parts of Doha, such as City Center, West bay, Souq Waqif and the Pearl, which houses primarily wealthy expats. A reflection of this geographic segregation is also the extremely polarized populations of wealthy Arab and non Arab citizens, on the one hand, and temporary migrant laborers on the other.

Doha, like Dubai (Vora 2013), carries a large segment of South Asia, something which is indexed by the linguistic, sartorial, religious and commercial forms visible in the city. These people are considered "foreign residents" (Nagy 1998), in the sense that they form the Gulf's non-citizen population. This term points to the ways this population, although it has contributed and continues to contribute to the development of the Gulf, has remained long-standing residents of the region. In this sense, they are considered as "builders of the nation" rather than "fellow nation builders" (Ahmad 2015: 25) and they are, thus, deemed "foreign" by Gulf states and citizens.

The rationale behind this sort of treatment is because foreign residents' work is considered as being contracted by-rather than contributing to-the nation. Foreign residents' changing status is reflected in the terms by which they came to be referred, including "migrant laborers," "guest workers," and "expatriates." A wide range of official policy documents, such as migration and residency laws in both the Gulf and migrant-sending countries, labor recruitment agencies, embassies and consulates as well as state institutions, including the police, border patrols and ministries of the Interior, Foreign Affairs, and Social Affairs, developed disciplined foreign residents into "temporary labor migrants".

The kafala system is the epitome of these laws and policies. The basic idea behind this kafala system is that, in order to work and reside in the Gulf, foreign residents require a residency permit, which they can only obtain by entering into a kafala arrangement with someone who has the rights to act as their kafeel, namely, their sponsor and guarantor (Ahmad 2015: 38-39). Gulf states confer this right upon citizens in good civic and legal standing, and to a far more limited extent, upon wellheeled foreign residents. They are allowed to stay in the Gulf for periods of time delimited by the labor contracts they enter into with individual citizens and institutions. Emerging in tandem and parallel to the Gulf countries' state infrastructure, the kafala system plays an integral role in bolstering the existing division of power between citizens and foreign residents, and in ensuring the impermanence of the 
region's non-citizens (Gardner 2015: 54-55). Overall, labor recruitment or 'manpower' agencies, travel routes, and the kafala system existing today are predicated on previous sets of inter regional networks, institutions, and legal contract systems.

Sociocultural and anthropological research on migrants in the Gulf tends to assume rather than analyze the processes whereby the kafala system disciplines foreign residents into temporary labor migrants (Osella and Osella 2008, 2012). In so doing, they consider migrant populations as a largely undifferentiated population. Whether from India, the Philippines or Egypt, foreign residents are posited as having similar motivations and decision-making patterns, primarily based on the Homo Economicus model, namely a model which is premised upon the idea that people migrate from their country of origin to a different one, in order to improve their (and their families') finances (Block 2018; Gardner 2015: 48; Lorente 2017). Furthermore, this type of research tends to consider foreign residents as rational, calculative actors who make decisions to maximize their individual self-interest. Another type of research focuses on relations of oppression with a special emphasis on the effects of foreign residents' discipling as temporary labor migrants (e.g. Longva 2005; Gardner 2015). These works analyze foreign residents' experiences of hierarchical, racialized, and exploitative labor relations in the Gulf. Many provide persuasive arguments about how these asymmetrical relations stem from the kafala system.

Apart from interregional trade, another factor that has a bearing on the shaping of these relationships is the broader socio-political system that disciplines foreign residents as temporary labor migrants. Even though foreign residents have no recourse to citizenship, namely to de jure belonging, they develop de facto forms of sociobelonging and identification in the Gulf. Their acute awareness of the Gulf's cosmopolitan past and present, and their recognition of their own contribution to the region's development shape their sense of identity and belonging and provide a basis from which they claim to be in and of the Gulf. A case study that illustrates this point is Osella and Osella's (2008) work, in which the Koyas ${ }^{2}$ of Kerala consider the Gulf as part of Kerala, and not as a separate area. Along the same lines, the kafala system unites these temporary migrants and it instills in them a racial consciousness that undergirds the development of South Asian diasporas.

Under the Qatari government, companies can only obtain Block Visas ${ }^{3}$ from certain countries - therefore even if QDVC, one of the biggest local construction conglomerates, ${ }^{4}$ wanted to recruit from Europe, they legally would not be able to. Recruitment of workers through Block Visas is mainly from developing Asian countries, such as India, Nepal, Bangladesh and Pakistan. Therefore, a large proportion of the workers employed are often more vulnerable, for example, they do not speak either English or Arabic, meaning they do not have the working languages of their management and this can create issues in understanding and communicating tasks,

\footnotetext{
2 Muslim Indians, who live in Kozhikode, Kerala.

3 A "block visa" is a simple application for positions on the basis of numbers of people with specific sociodemographic background, e.g. 10 male carpenters from Pakistan, 5 male electricians from India, etc.

${ }^{4}$ http://www.qdvc.com/index.php/en/.
} 
and reading and understanding contracts, contributing to potential exploitation of the hired workers. When this is combined with poor labour law enforcement, the employee issues are further entrenched (Neale 2017).

In Qatari workplaces, there are "language policies" (Shohamy 2006; Johnson 2013), a concept under which I understand what institutions do officially to determine and alter language choice and language use in public contexts (Kirilova and Angouri 2017: 540). A language policy mobilizes specific institutional discourses on how the policy should be implemented and what the repercussions of nonadherence might be. Language policy has become relevant in Qatari blue-collar workplaces in two ways: (1) as a discourse in mainstream media in Qatar, because Amnesty International researchers found that virtually no construction workers who do not occupy management or "staff" positions in Qatar speak Arabic or English to the level required to properly explain a complex labour complaint. ${ }^{5}$ And (2) in Qatar Labor law, there is an explicit reference to language policy that pertains to work contracts, which reads as follows:

Point 4: All work permits, instructions, notices, schedules and other documents issued by the employer in the application of this Act shall be in Arabic. Translation to other languages may be added, but the Arabic language shall be the only language recognized in case of disputes. ${ }^{6}$ In addition, English is also widely spoken as it often forms a common denominator language among the Qataris and the large expatriate population. Farsi, Urdu, Hindi, Malayalam, and Tagalog are also common due to the composition of the expat population. Arabic, the language of Islam, linguistically unites expat Muslims and citizen Muslims when English is less well understood. ${ }^{7}$

However, when it comes to language policy relevant to everyday oral communication in the workplace, the language policy can be more implicit and can only exist in hidden norms or unwritten rules. The basic reason for this is the fleetingness and lack of documentation of such communication, a fact that allows people to be creative, spontaneous and goal instead of policy-oriented. As such, language policy needs to be fleshed out ethnographically (cf. Johnson 2009).

Having provided an essential background on the discourses and policies pertaining to the hiring and life of labor migrants in Qatar, I now turn to the analysis of their communication in their workplace with a focus on their spatial and scale orientation, including all material and social affordances, such as artifacts, objects and social networks that are referenced and matter for the interlocutors.

\footnotetext{
5 https://dohanews.co/small-team-language-barriers-hamper-qatars-labor-inspection-process/ (accessed on $15 / 1 / 2018)$.

${ }^{6}$ http://www.ilo.org/dyn/natlex/docs/WEBTEXT/49369/65107/E87QAT01.htm ～(accessed on 15/1/2018).

7 http://qatarlaborlaw.com/ (accessed on 15/1/2018).
} 


\section{Spatial repertoires in the workplace}

Everything can become communicative based on the indexicality achieved in situated interactions over time. In the context of time/space compression and the resulting simultaneity that is implied in spatial repertoires, we need to consider participants outside the immediate physical context of interaction. A layered simultaneity acquaints us to the fact that there are multiple scales of influence from places and times of different distance and proximity (Blommaert 2007; Pennycook and Otsuji 2014, 2015; Canagarajah 2017). The contexts or factors that mediate and shape multilingual interaction can belong to different scales of consideration, nested or overlapping with one another. Such types of interactions construct the very concept of workplace for workers. As such, places are where (location) language practices (locution) occur as people bring their own trajectories into relation with the people and the objects around them (Pennycook and Otsuji 2014: 165). These places are also realized through the various social meanings that people in the workplace construct through their communication. In this paper, three such meanings will be analyzed that have been found relevant to and common among all participants: rubbing along, mediating differences, and intercultural embracement.

\section{Rubbing along}

Rubbing along is identified with a casual and friendly encounter among interlocutors (Watson 2009: 137) and it has been found as one of the themes emerging from my data. The two interlocutors here, Bhavin and Himmat, both of whom are builders in their early twenties from West Bengal, carry a box from one side of the construction site to the other and in the act of transfer they have a short dialogue with a spatial repertoire consisting of Bengali and Hindi utterances as well as a switch between linguistic and paralinguistic codes. Despite their common Indo-Aryan origins, Hindi is usually understood by Bengali speakers due to their exposure to Hindi-speaking Bollywood programs and the status of Hindi as a widely spoken language that is official in many states, while Bengali is not usually understood by Hindi speakers, unless they have interacted with them.

\section{Excerpt 1}

(B: Bhavin, H: Himmat)

Bengali: Italics; Hindi: Plain

[Translation in square brackets]

((Transcriber's comments in double brackets))

\section{B: Cholo bohon kori bon ta k okane (Bengali)}

[B: Let's carry the box over there] 
2. H: ((Indian head wobbling with high brow and relatively fast tempo while helping Bhavin carry the box)) aur phir ham bas ja sakate hain (Hindi)

$\mathrm{H}$ : ((head wobbling with high brow and relatively fast tempo while helping Bhavin carry the box)) [and then we can just go to the bus]

3. B: ((head wobbling with a smile))

In this interactional episode between Bhavin and Himmat, there is a combination of verbal and nonverbal communicative resources, which in unison create rubbing along. The fact that indexes this relaxed atmosphere between the two workers is the head wobbling in both lines 2 and 3 pointing at an affective stance of agreement, liking and friendliness between Bhavin and Himmat. A fast and continuous head wobble in India $^{8}$ means that the person really understands (cf. Seow 2017; Storti 2015). The more vigorous the wobbling, the more understanding there is. A quick wobble from side to side means "yes" or "alright". A slow soft wobble, sometimes accompanied by a smile, is a sign of friendship and respect.

Another argument in favor of this positive affective stance is the fact that both Bengali and Hindi utterances are used here in an almost latching way, meaning that Himmat completes Bhavin's utterance in line 1, a fact that is met with appreciation and enthusiasm indexed through the head wobbling with a smile in line 3 . In this sense, both the paralinguistic and the linguistic resources combined here form significant dimensions of the spatial repertoire used by the two interlocutors, because they are embedded in the space and time contingencies in which their carrying activity occurs. The spatial repertoire used here can explain the competence that these two speakers have, which allows them not only to communicate with each other but also to successfully execute a working task they have been assigned to do. The carrying of the box is a communicative activity that requires certain objects, words and, in short, some sort of coordination. The latter is evident in the carrying action per se in addition to the head wobbling. It is noteworthy that the English word "box" is used here against the backdrop of Indian utterances, most probably because it is a short one and easy to pronounce, apart from the fact that it is internationally recognizable. The conditions of possibility that enable their communication-the material artefacts, the spatial layout, the people's movements, create the affordances of the spatial repertoire (Pennycook and Otsuji 2017: 436).

In short, what we have seen in this episode is an example of how participants have adopted reciprocal strategies in joint activities that have led to the emergence of a multilingual and multisemiotic spatial repertoire employed by blue-collar workers in a mundane activity taking place in every construction site, which is that of carrying a box. It is a good example of what Pennycook and Otsuji (2015: 2) have called "metrolingual multitasking", namely the way in which linguistic resources, everyday tasks and social space are intertwined" (ibid.) This is in alignment with relational talk (Holmes et al. 2011: 83), whereby white-collar employees establish rapport and collegiality primarily though language; however, my data here suggest that blue-collar workers, due to the manual nature of their work, seem to make more

\footnotetext{
${ }^{8}$ For a lay explanation of the different types of Indian nodding, see the following video: https://www. youtube.com/watch?v=0RaBxH_MKQI (accessed on 11/1/2018).
} 
pronounced use of the spatial layout of their work environment by moving around material artefacts and coordinating this movement via (body) language.

Apart from rubbing along, however, more often than not multilingual construction sites can host misunderstandings (Holmes and Stubbe 2015: 137-163), which need to be dealt with on the spot and relatively fast, given the time restrictions of the projects as well as the stress that is put upon all parties involved. Such an example is analyzed in the next episode.

\section{Mediating differences}

Mediating differences can be seen as a practice, whereby an attempt is made on behalf of interlocutors to intervene, in order to solve miscommunication and to rectify problematic talk. In this interactional episode, the four interlocutors, Vihaan and Madhup, who are builders from Kerala, Ojas, who is the team supervisor and also from Kerala, and John from Adelaide, Australia, who was on the workplace on the day of the recording to inspect the work and the workers. All four interlocutors are caught up in a heated debate that arose after Ojas, the team supervisor, realized that a worker had put the wrong tile on a surface in the construction site.

\section{Excerpt 2}

(O: Ojas, V: Vihaan, M: Madhup, J: John)

Malayalam: Italics; Tamil: Bold; Hindi: Underlined; English: Plain

[Translation in square brackets]

((Transcriber's comments in double brackets))

1. O: Athengane ithu avanu ee sthalath vechathu? (Malayalam)

O: [Ok, so did this happen? Who put this ((pointing at the misplaced tile)) in the wrong spot?]

2. V: Atu enakku illai, aiyā, Madhup atai ceytār. (Tamil)

V: [It was not me, sir, Madhup did it.]

3. O: Mādhūp, nee ano ithu ivide vechathu? (Malayalam)

O: [Madhup, did you put this here?]

4. M: Nahin, yah me nahin tha; mainne ise Vihaan ko de diya aur usne (Hindi) messed up (English). 
M: [No, it was not me; I gave it to Vihaan ((pointing at Vihaan with his right index finger)) and he messed it up.]

5. O: Sari, ningal randu perum ithu ivide ninnum neekkam oneyyanamennu njan agrahikkunnu! (Malayalam).

O: [Ok, I want both of you to remove it and then out of here now! ((in an angry tone and addressing both Vihaan and Madhup by pointing at both with his two fingers))]

6. O: Parasparam samsarikkuka ningal ashayavinimayam nadathumpol, kooduthai thettukal illathe trackil varan njan agrahikkunnu (Malayalam), ok (English)? $O$ : ((While both Vihaan and Madhup have bent their knees and they are looking at the tile)) [Go talk to each other and when you communicate, I want you back on track with no further mistakes - ok?]

7. J: ((Using side-to-side hand wave towards all three)) No, send them to help around crane 1 area ((addressing Ojas and pointing towards crane 1 area with his right hand))

Ethnographically speaking, there is a history of disagreements and fights between Vihaan and Madhup both inside and outside the construction site, something which has led Ojas to always ask John to join him, whenever Ojas feels that there is looming trouble between Vihaan and Madhup. This contextual bit of information is vital for delimiting the spatiality of the repertoires used here and it is important also in order to understand what is going on. It is noteworthy that throughout this episode John, who has the most power as he is the most qualified of the interlocutors, remains silent with the exception of line 7, where he instructs his subordinate Ojas to send the two workers, Vihaan and Madhup, to another area in the construction site to help with other tasks. This is a typical communicative pattern I have noticed in my data; whenever there is a dispute or a disagreement or a complaint or a problem, team managers are the ones who are seemingly orchestrating the more often than not heated discussions and they try to calm all interlocutors down by allocating tasks and roles to the workers.

The interaction starts with Ojas, who speaks in Malayalam addressing both Madhup and Vihaan; the two deictics used by Ojas, "this" referring to the incident of misplacement of the tile and "this" referring to the misplaced tile itself, are uttered in Malayalam accompanied by a pointing gesture in the second "this" to focus the two workers' attention to the problem. The use of Malayalam here is expected, given that all interlocutors (apart from John, who, however, is more of an eavesdropper in this scene) speak the language, as they are Keralites.

Nonetheless, the spatial repertoire is further enriched by Tamil, which is the preferred code of communication for Vihaan in line 2. His refusal to take responsibility and his simultaneous accusation of Madhup in Tamil, a language that Madhup does 
not understand, serves as a self-protection strategy on behalf of Vihaan, in order for him to avoid any potential punishment due to his mistake. Such punishment could be his being transferred to another group with a stricter supervisor and/or heavier tasks in the construction site. At the same time, because Vihaan does not wish to confront Madhup directly and have a verbal dispute in front of his supervisor, he chooses to use a code that Madhup does not understand and his supervisor, Ojas, does, in order to create alignment with the latter. In this way, Vihaan tries to forge a strategic alliance with the more powerful actor in the interaction and, subsequently, to be on the safe side. It is notworthy that, contrary to white-collar enviroments, where employees avoid laying blame on other members of teams by paying attention to the face needs of team members (cf. Holmes and Stubbe 2015: 141), here Vihaan accuses Madhup explicitly.

From his side, Ojas tries to keep a balance between the two by asking Madhup (instead of accusing him directly and, in this way, to give the impression that he is giving into Vihaan) whether he misplaced the tile. In this sense, Ojas can be seen as keeping the team morale high, a practice that has been found characterizing whitecollar work environments (ibid.) Madhup uses a repertoire with Hindi and English words as his preferred code of communication in line 4 to accuse Vihaan. Madhup also uses an indirect way of accusation as he uses a narrative involving both himself and Vihaan and, at the end thereof, he employs an English utterance (messed up), which serves both as the resolution of the story and Madhup's evaluation of Vihaan's activity. The phrasal verb "to mess up" is used occasionally in construction sites in Qatar by both blue-collar laborers and white-collar professionals, so it is not surprising that it is used by Madhup.

Ideologically speaking, Hindi and English are considered as rather formal linguistic varieties when used by Indian blue-collar laborers. Hence, their choice here can be interpreted as an orientation, on behalf of Madhup, to a higher-level sociolinguistic scale or to "upscaling" (Blommaert 2007, 2010), in order to create an austere and serious framework, in which his utterance will carry more gravitas and, hence, he will be more persuasive to his interlocutors. Apart from this shifting between formal linguistic varieties, Madhup also uses pointing (with one finger) in his utterance as a strategy to enhance his position that the misplacement of the tile is Vihaan's responsibility. At the same time, however, he indexes strong impoliteness, as pointing with one finger is considered to be impolite in Indian culture (Lewis 2000: 161). His combination of linguistic and exolinguistic choices creates a spatial repertoire that inscribes him as a serious and powerful (indexed by his perceived legitimation to point at other people and, hence, to decide when he can be impolite) interlocutor, who realizes (exo)linguistically the idea that the best defense is offense.

In order to ease the tension that has been created in the interaction due to bidirectional accusations against each other by Vihaan and Madhup, Ojas tries to settle things by requesting in Malayalam that both laborers remove the misplaced tile, they reconcile their differences and then they come back to work. His angry tone in line 5, coupled with pointing at both with two fingers, a gesture which is used with subordinates in Indian culture (Lewis 2000: 162), are justified by his powerful position and the responsibilities that stem from it for a safe and successful completion of the work in progress. At the same time, it indexes his 
communicative competence in such a context: he knows that if he used a softer tone, he would not be taken seriously by his subordinates and, accordingly, his orders and instructions would not be followed resulting in a potential delay in the delivery of the project and its parts.

The fact that Ojas has communicative competence is verified by the fact that, immediately after his utterance in line 5, both Vihaan and Madhup start focusing on the tile without objecting to him or complaining. Their reorientation from confronting each other to actually standing next to each other and focusing on their common task, which is the removal of the misplaced tile, is the outcome not only of Ojas' use of Malayalam, a code they both understand, but also of his direct and unmitigated orders vis-a-vis both Vihaan and Madhup, which again are part of the professional spatial repertoire used in blue-collar workplaces; the lack of mitigation in giving instructions or orders owes to the fact that these must be followed or executed immediately, according to my ethnographic notes. This immediacy is further stressed through the temporal adverb "now", which inscribes the utterance in a temporal scale of the time the utterance is made by Ojas.

This direct repertoire carries on in line 7, where John's side-to-side hand wave (meaning "hello" in the Western world) is interpreted in the Indian culture as "no" or "go away" (Knapp et al. 2014: 373-375). Through this gesture, John indexes his disagreement with Ojas with respect to where Vihaan and Madhup should be sent; to emphasize his disagreement, he verbalizes it in English with the word "no", and he further orders Ojas in English to send Vihaan and Madhup to crane 1 area to help with various tasks. This combination of nonverbal and verbal codes serves to index John's cultural knowledge of Indians as well as to ascertain his power. John can understand Ojas' use of Malayalam because, according to his ethnographic profile, has been working with Keralites for 12 years, therefore he can understand Malayalam.

Throughout this episode, there is an interesting and dynamic negotiation of power among the four interactants with respect to who has the right to do things with words, such as accusations and giving orders and instructions, which are vital for the successful completion of the project taking place at the construction site. This negotiation takes place both linguistically (via Malayalam, Tamil, Hindi and English words) and exolinguistically (via pointing) and the spatial repertoires that are used here draw on a number of scales: the formality-less formality one (this is evident in the case of the English words and utterances versus the rest of the utterances coded in Indian linguistic varieties), the power-less power one (related with the professional status of the person, who uses the spatial repertoire each time; the most powerful one is John, less powerful interactant is Ojas as the team supervisor, and the two least powerful interactants are Vihaan and Madhup, who manage, however, to have their voices heard in the context of defending themselves and putting the blame on each other). In this way, they index their agency with respect to communication in the workplace.

Finally, a relevant scale that the spatial repertoires of the interlocutors draw on is the directness-indirectness one, which is relevant to the shift between linguistic and exolinguistic repertoires; pointing in all its discussed forms can be seen as more 
direct than the use of linguistic utterances, something which is evident in the data; whenever there is pointing, there is always an immediate reaction.

The third type of jointly constructed social meaning that has been found in my data set is what I call "intercultural embracement." The episode used to illustrate this is analyzed immediately below.

\section{Intercultural embracement}

Intercultural embracement is the outcome of interlocutors' drawing on various cultures in order to communicate with each other, to create an in-group code and, subsequently, to reinforce a multicultural group identity. The interlocutors of this episode include Kostas, a senior engineer of Greek origin, Faiyaz, the team supervisor from Madras State, and the blue-collar laborers Divit from Andhra Pradesh and Nil from Kerala, who are having a linguistically rich encounter with important intercultural implications:

\section{Excerpt 3}

(K: Kostas, F: Faiyaz, D: Divit, N: Nil)

Malayalam: Italics; Greek: Bold; Hindi: Underlined; English: Plain; Japanese: Bold italics; Arabic: *between stars*

[Translation in square brackets]

((Transcriber's comments in double brackets))

1. K: Malakes, in $15^{\prime}$ break; gather here and leave sāvadhānaim sāvadhānam (Malayalam); $1 \mathrm{~h}$ for inemuri (Japanese) and then you come back. *Yalla* (Arabic), go now!

[K: dudes, in 15' you have a break; gather here and leave slowly slowly; you have $1 \mathrm{~h}$ for relaxation and then you need to come back. Come on, go now!]

2. F: Brek ke lie samay; tum log, lo (Hindi) inemuri (Japanese) ek ghante ke lie aur jana! (Hindi)

F: [Time for break; take inemuri for one hour and don't fall asleep!]

3. D: Nil, kya aaj ke lie tumhaaree koee yojana hai (Hindi), re malaka (Greek)?

D: [Nil, do you have any plans for today, dude?]

4. N: Mera aaj ya tumhaara aaj? (Hindi)

$\mathrm{N}$ : [My today or your today?] 
((Faiyaz, Nil and Divit are laughing))

5. D: Ham usee desh se kaise jude hue hain main kabhee nahin samajhoonga (Hindi)

D: [How can we belong to the same country I'll never understand]

\section{((Faiyaz, Divit and Nil are laughing))}

At the very beginning, Kostas in a rather unusual interactive move for a senior engineer on site informs the team that their break will start in 15'; it is unusual, because what usually happens is that the senior engineer notifies the team supervisor about break time and he, in turn, informs the blue-collar laborers in an Indian language. The direct notification on behalf of Kostas can be seen as an example of "repressive discourse" (Holmes and Stubbe 2015: 100), which characterizes primarily white-collar communication. It is a covert means of exercising top-down or coercive power, in which he minimizes overt status differences and emphasizes solidarity, in order to gain his interlocutors' willing compliance and goodwill. Kostas' spatial repertoire includes a range of diverse and culturally specific words and expressions with interesting connotations in terms of scales. First of all, the term "malakas" (vocative plural: "malakes," as used here in line 1) literally means "a person who satisfies themselves via masturbating", but over the years the word's semantic field has been expanded and, nowadays, depending on the context, it can mean "idiot," "superficial," "asshole," "careless," or "mindless" (Kamilaki et al. 2015: 93-4); nonetheless, it can also be used as a term of endearment and ingroup marker to signify solidarity; the meaning in that case would be similar to "mate" or "dude." It is a widely recognizable Greek word, but as a researcher and native speaker of Greek, I was really surprised when I found out that Kostas uses this word extensively when addressing his subordinates. Most surprisingly, I came to discover that some blue-collar laborers use this label to address each other, sometimes foregrounded by the emphatic particle "re" (cf. Karachaliou and Archakis 2012), which cannot be translated in English. In the case of Kostas, in an interview I had with him he told me that he uses malaka (sg.)/malakes (pl.) with the meaning of "my friend"/"my friends," so he uses the term as a term of endearment, because he cannot remember the names of the laborers. However, at the same time, he wishes to have interpersonal contact with them, contrary to other Western engineers, who prefer to interact with laborers indirectly, via the team supervisors. In fact, Kostas has reported that he is proud of himself having taught the use of this label to some laborers. The latter have found the word easy to use in similar contexts, hence they use it with their colleagues in the construction site and, sometimes, with their friends outside work as well. For me as a native speaker of Greek, the use of the address term phrase "re malaka" by Divit in line 3, is unexpected given its cultural specificity; nonetheless, if we take into consideration Kostas' teaching of the word to the workers, it makes sense. In line 3 the intended meaning of the phrase is "dude." In this sense, both Kostas and Divit relate their meaning of group solidarity and 


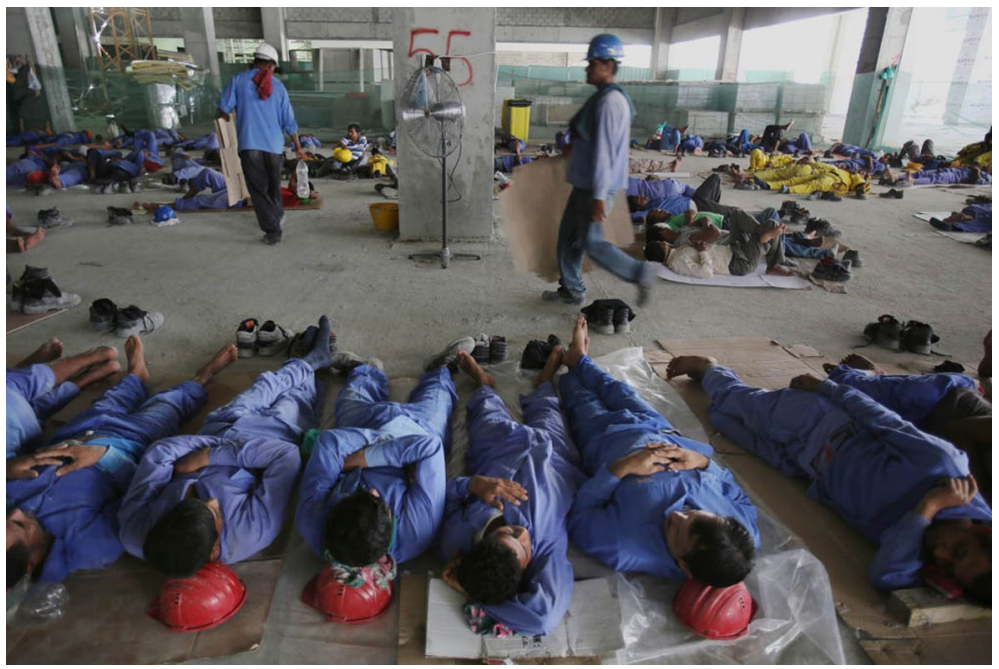

Figure 1 Indian laborers’ inemuri (@ Google Images)

their identities to other places and times beyond the situated interaction: Kostas can be argued to ascertain his Greek identity through the use of this culturally specific term, while Divit seems to claim some of the alleged coolness attached to this Greek word.

The upscaling (Blommaert 2007, 2010) of Kostas' repertoire is also diversified through the use of the Malayalam expression to refer to the idea of leaving slowly, by using a term that he has been able to learn in the construction site after extensive interaction with Keralites, whose native language is Malayalam. The use of the Malayalam term serves to impose some sort of order to the laborers, who tend to rush whenever they are notified that it is break time; at the same time, it can be argued that the term is used by Kostas as an attempt to be self-sarcastic, because he has been told that his Malayalam (especially his phonetics) is very bad. Through the use of the Malayalam expression here he takes an entertaining stance whereby he tries to entertain his interlocutors for all of whom the day so far had been very busy and, at the same time, he compromises himself and his attempt to learn the language on the spot. Nonetheless, he does not compromise his overall attempt to look cosmopolitan and culturally knowledgeable and this is evident in drawing on the sociocultural linguistic scale of Japan through the use of the term "inemuri". Another very culturally specific term with no exact translation in English (the most approximate one would be "spacing out" with your eyes closed), it is one that Kostas learnt when he visited Japan and he liked it so much (because it reminds him of the Greek slang sentence "ine muri", which roughly translates into "somebody is cool", but the meaning can vary significantly, again depending on the context) that he has started using it in his repertoire both inside and outside his workplace. In fact, this word has proved to be popular with the Indian laborers because, like "malaka," it has been picked up very easily by them, a fact that is evident through its use by Faiyaz in line 2. Inemuri means that you space out in public, in order to collect your thoughts and 
energy for your next assignment, and this is done with your eyes closed; a person who does inemuri might seem to others that they have fallen asleep, but Japanese consider this state as non sleep. ${ }^{9}$

Given that this is essentially what happens among Indian blue-collar laborers in many construction sites across Qatar (see Figure 1), Kostas has decided to refer to this state as inemuri by choosing again a term, which he finds uniquely appropriate and easy to articulate. Finally, his spatiality includes the Arabic particle "yalla,", which means "come (on)," and it is used extensively by Arabic speakers of all ages in Qatar. Due to its phonetic proximity with the Greek equivalent word "ela," which also means "come (on)," and the fact that he works in Qatar, Kostas uses this word in his utterance.

With respect to the rest of the spatial repertoires, even though the dialogue among Faiyaz, Divit and Nil takes place primarily in Hindi with the insertion of one Japanese and one Greek word, there is a potential misunderstanding between Divit and Nil due to their different temporal scales pertaining to their areas of origin. More specifically, Andhra Pradesh, from which Divit hails, follows the Shalivahana Saka calendar, while Kerala, from which Nil originates, has its own regional calendars. While they follow the same naming system for months, Andhra Pradesh follows a lunar calendar, while Kerala has a solar calendar. ${ }^{10}$ Both speakers know about this time-related cultural difference, hence Nil asks the question in line 4, which initiates latent humor; the implication here is that due to the wide range of cultural differences all over India whenever Indians talk about seemingly uncontroversial topics, such as time, they always need to localize their discussion by drawing on culturally specific temporal scales, something which is not necessary in other parts of the world. It is this need for localization that leads Divit to express his surprise for the unity of the country in line 5 , despite these major differences that can lead to confusion and misunderstandings.

It is interesting to note the controversy between the code and the message in this utterance; the code used is Hindi, which is used in this episode as a lingua franca for the Indian interactants, but the content of the utterance, especially in line 5, challenges this unity. Such controversy can be claimed to enhance the challenge in which Divit poses his and Nil's national identity and, in this way, to negotiate its content, something that is found in the data that follow this episode, which, however, will not be analyzed here due to word limitations.

Overall, the different dimensions of scaling which are mobilized here inscribe intercultural embracement among the four interlocutors, who seem to celebrate these terms and expressions taken from cultures different from their native ones and to construct a collective multilingual and intercultural group identity.

To summarize, in the three episodes analyzed here it becomes evident that the activities of rubbing along, mediating differences and intercultural embracement respectively are constructed through a pastiche of social meanings which are indexed through a wide range of spatial repertoires used by all types of participants

\footnotetext{
9 http://www.bbc.com/future/story/20160506-the-japanese-art-of-not-sleeping (accessed on 15/1/2018).

$10 \mathrm{https} / / / \mathrm{www}$.quora.com/What-are-the-cultural-differences-between-Kerala-Tamil-Nadu-Andhra-Prade sh-and-Karnataka (accessed on 11/1/2018).
} 
in the workplace. The latter draw on various spatiotemporal scales and realize these repertoires via different linguistic and exolinguistic codes. In this sense, blue-collar workplaces can be seen as an agentively constructed space through sociolinguistic processes where "knowledge of language is rooted in situation and dynamically distributed across individuals as they engage in practices" (Blommaert et al. 2005: 205). Having said that, the bottom-up language policies pertinent to the blue-collar workplaces are much more complex than the ones found in documents. In the last section of this paper, I elaborate on the implications of this complexity in terms of theorizing language policies.

\section{Conclusion}

The ethnographic approach of language policy in blue collar workplace helps us identify and understand gaps from policy to practice in terms of top-down and bottom-up activities and processes. The analyzed unscripted communicative practices of blue collar workers in Qatar, which are softly managed (Duchêne and Heller 2012: 331-3) run contrary to the linguistic policy documents pertaining to workplaces in Qatar that prescribe primarily the use of Arabic and English; the lived communicative "practices in place" (Pennycook and Otsuji 2014: 168) of blue-collar workers and the people, with whom they interact, is much more complex, in the sense that their spatial repertoires draw on different cultures and various modes of communication, including linguistic and exolinguistic ones, that have local prestige (cf. Sallabank 2010) among their users. In this sense, local actors become involved in crafting spaces for their minoritized linguistic and semiotic resources in a thoughful, committed and creative way (cf. Hornberger et al. 2018), as has become apparent in the analysis of all examples. In the blue-collar workplace, diversity is usually represented as a set of challenges and anticipation of poor performance or "non-fit."

My analysis has shown how this blue-collar workplace in Qatar reverberate with a range of sociolinguistic resources and spatial repertoires deployed by interactants to achieve different goals, such as rubbing along, mediating differences and establishing intercultural embracement, as ways of easing tensions that are inevitably created in such a demanding workplace in Qatar, like an outdoor construction site. The mobilization of these resources also serves the inclusion or exclusion of others from the communicated message, as we saw in the example of Vihaan and Madhup, and further manages to restrain the circulation beyond specific teams marked through the ability to access information, as was evident in the case of Kostas, Faiyaz, Nil and Divit. This diversity, which is marked through the use of shared and thus recognizable ingroup markers creates diversity, which of course does not mean that there is no power imbalance between core and peripheral languages.

As is evident in the data analyzed above, the dominant language of communication is primarily English, given that the senior engineers, who essentially delimit the supervisors' and blue-collar workers' roles, tasks and activities in the workplace, use it as their preferred code of communication. However, on many occasions their English is enriched through key words and expressions to maximize their communicability and their subordinates' productivity and efficiency. 
In this sense, English is projected as a language that everyone needs and that all should learn in basic education worldwide, a "lingua nullius" (Phillipson 2017: 315). Nonetheless, it also gets linguistically and semiotically enriched, a fact that makes power hierarchy more dynamic and also negotiable and challengeable in situ. This is something that has become very clear in the example of Vihaan and Madhup but also in the case of Ojas and John. The implication of this is that language policies at the level of mundane communication in blue-collar workplaces are shifting and are co-constructed by labor and their supervisors alike, a fact that renders them much more interculturally accommodating and semiotically flexible than the authoritarian language policies prescribed by the State of Qatar. In this sense, the Qatar outdoor construction site, analyzed here, stands as a powerful example of how local and historically disenfranchised groups can redefine traditional power relationships, and develop and influence policy to support their specific communication goals (cf. Warhol 2012: 236).

Politically influential classes of merchant elites have been reported to discourage the development of solidarity amongst foreign residents whether by recruiting migrants of different national, religious and linguistic backgrounds or by discouraging the multiple renewals of contracts or by even actively repressing any forms of social or community organization that migrants might want to engage in (Ahmad 2015: 29). Foreign residents' internal differentiation along occupational and class lines may explain this phenomenon. Relevant research points to how middle or upper-middle class foreign residents may perpetuate hierarchical and exploitative labor relations by acting as intermediaries and implementers, for example managers and supervisors in their systems (Gardner 2008). However, my data have shown that through their sociolinguistic practices in the workplace, people from diverse ethnolinguistic backgrounds do in fact manage to establish solidarity and, even, harmonization (cf. Makoni 2016), amongst themselves, as was the case with Bhavin and Himmat and primarily with Kostas, Faiyaz, Divit and Nil. Their spatial repertoires, which couple various linguistic and exolinguistic codes, manage to bring them together into two respective groups whose members get along pretty well and can, therefore, be efficient in terms of executing their tasks. On the basis of these examples, it seems to be the case that linguistic practices are not always in alignment with wider sociopolitical discourses circulating around blue-collar workplaces and, in order to be able to make such claims, one of the most efficient ways is to research these spaces ethnographically and to be sensitized to people's agency and creativity.

The implications of this study for language policy research and praxis are important as my ethnographic research on blue collar workplace in Qatar has taken language, communication, and discourse practices into account in explicit ways, in recognition that social actors' ways of being and doing are intimately tied to and indeed constructed by their ways of communicating (cf. Hornberger et al. 2018: 153-154). I have shown that the blue-collar workspace can be seen as an ideological and implementational language policy space, where scalar, layered policies and practices influence each other, mutually transforming ideology through implementation and resistance and vice versa. 
Acknowledgements Open Access funding provided by the Qatar National Library. This study was made possible by a Junior Scientists Research Experience Program grant (JSREP 4-009-6-003) from Qatar National Research Fund, a member of Qatar Foundation. I would like to thank my research assistants Vani Sankar and Aramathi Rao as well as Nuri Ismail and Hameeda Kaiprath Puthiyapurayil for their help with the data. In addition, many thanks go to Kellie Gonçalves, Daan Hovens and the anonymous reviewers for useful feedback on earlier drafts of this paper. The statements made herein are solely mine.

Open Access This article is distributed under the terms of the Creative Commons Attribution 4.0 International License (http://creativecommons.org/licenses/by/4.0/), which permits unrestricted use, distribution, and reproduction in any medium, provided you give appropriate credit to the original author(s) and the source, provide a link to the Creative Commons license, and indicate if changes were made.

\section{References}

Ahmad, A. (2015). Beyond labor: Foreign residents in the Persian Gulf states. In M. Kamrava \& Z. Babar (Eds.), Migrant labor in the Persian Gulf (pp. 21-40). London: Hurst \& Company.

Allan, K., \& McElhinny, B. (2017). Neoliberalism, transnationalism and language. In S. Canagarajah (Ed.), The Routledge handbook of migration and language (pp. 79-101). New York: Roultedge.

Baker, C. (2011). Foundations of bilingual education and bilingualism (5th ed.). Clevedon: Multilingual Matters.

Blackledge, A., \& Creese, A. (2017). Translanguaging in mobility. In S. Canagarajah (Ed.), The Routledge handbook of migration and language (pp. 31-46). New York: Routledge.

Block, D. (2018). Political economy and sociolinguistics. Neoliberalism, inequality and social class. London: Bloomsbury.

Blommaert, J. (2007). Sociolinguistic scales. Intercultural Pragmatics, 4(1), 1-19. https://doi. org/10.1515/ip.2007.001.

Blommaert, J. (2009). Ethnography and democracy: Hymes's political theory of language. Text \& Talk, 29(3), 257-276. https://doi.org/10.1515/text.2009.014.

Blommaert, J. (2010). The sociolinguistics of globalization. Cambridge: Cambridge University Press.

Blommaert, J. (2013). Language and the study of diversity. Working Papers in Urban Language \& Literacies, 44(1), 90-113.

Blommaert, J. (2014). From mobility to complexity in sociolinguistic theory and method. Working Papers in Urban Language \& Literacies, 135. https://www.tilburguniversity.edu/upload/5ff19e979abc-45d0-8773-d2d8b0a9b0f8_TPCS_103_Blommaert.pdf.

Blommaert, J., \& Backus, A. (2013). Superdiverse repertoires and the individual. In I. de Saint-Jacques \& J.-J. Weber (Eds.), Multimodality and multilingualism: Current challenges for educational studies (pp. 11-32). Rotterdam: Sense Publishers.

Blommaert, J., Collins, J., \& Slembrouk, S. (2005). Spaces of multilingualism. Language \& Communication, 25, 197-216. https://doi.org/10.1016/j.langcom.2005.05.002.

Blommaert, J., Spotti, M., \& Van der Aaa, J. (2017). Complexity, mobility, migration. In S. Canagarajah (Ed.), The Routledge handbook of migration and language (pp. 349-363). New York: Routledge.

Breeding, M. (2015). Corruption and capacity in regulating recruitment agencies. In M. Kamrava \& Z. Babar (Eds.), Migrant labor in the Persian Gulf (pp. 137-154). London: Hurst \& Company.

Canagarajah, S. (2013). Translingual practice: Global englishes and cosmopolitan relations. London: Routledge.

Canagarajah, S. (2017). The nexus of migration and language. In S. Canagarajah (Ed.), The Routledge handbook of migration and language (pp. 1-28). New York: Routledge.

de Certeau, M. (1984). The practice of everyday life. Berkeley: University of California Press.

Duchêne, A., \& Heller, M. (2012). Language policy in the workplace. In B. Spolsky (Ed.), The Cambridge handbook of language policy (pp. 323-334). Cambridge: Cambridge University Press.

Flick, U. (2004). Triangulation in qualitative research. In U. Flick, E. von Kardoff, \& I. Steinke (Eds.), A companion to qualitative research (pp. 178-183). London: Sage.

Fromherz, A. J. (2012). Qatar. A modern history. Washington, DC: Georgetown University Press.

Garcia, O. (2009). Bilingual education in the 21st century. Oxford: Wiley Blackwell. 
Gardner, A. (2008). Strategic transnationalism: The Indian diasporic elite in contemporary Bahrain. City \& Society, 20(1), 54-78. https://doi.org/10.1111/j.1548-744X.2008.00005.x.

Gardner, A. (2015). Why do they keep coming? Labor migrants in the Gulf States. In M. Kamrava \& Z. Babar (Eds.), Migrant labor in the Persian Gulf (pp. 41-58). London: Hurst \& Company.

Han, M. (2017). Trade migration and language. In S. Canagarajah (Ed.), The Routledge handbook of migration and language (pp. 258-274). New York: Routledge.

Hassa, S. (2012). Regulating and negotiating linguistic diversity: Top-down and bottom-up language planning in the Moroccan city. Current Issues in Language Planning, 13(3), 207-223. https://doi. org/10.1080/14664208.2012.722375.

Holmes, J., Marra, M., \& Vine, B. (2011). Leadership, discourse, and ethnicity. New York: Oxford University Press.

Holmes, J., \& Stubbe, M. (2015). Power and politeness in the workplace. A sociolinguistic analysis of talk at work. London: Routledge.

Hornberger, N., \& Cassels Johnson, D. (2011). The ethnography of language policy. In T. McCarty (Ed.), Ethnography and language policy (pp. 273-289). London: Routledge.

Hornberger, N., Tapia, A., Hanks, D., Dueñas, F., \& Lee, S. (2018). Ethnography of language planning and policy. Language Teaching, 51(2), 152-186. https://doi.org/10.1017/S0261444817000428.

Johnson, D. C. (2009). Ethnography of language policy. Language Policy, 8(2), 139-159. https://doi. org/10.1007/s10993-009-9136-9.

Johnson, D. C. (2013). What is language policy? In D. C. Johnson (Ed.), Language policy. Research and practice in applied linguistics (pp. 3-25). London: Palgrave Macmillan.

Jørgensen, N. (2008). Polylingual languaging around and among children and adolescents. International Journal of Multilingualism, 5(3), 161-176. https://doi.org/10.1080/14790710802387562.

Kamilaki, M., Katsouda, G., \& Vrahionidou, M. (2015). Piperi sto Stoma. Opseis ton lexeon-taboo sth Nea Elliniki (Pepper in the Mouth. Aspects of taboo-words in Modern Greek). Athens: Kalligrafos (in Greek).

Kamrava, M. (2015). Qatar: Small state, big politics. Ithaca: Cornell University Press.

Kamrava, M., \& Babar, Z. (Eds.). (2015). Migrant labor in the Persian Gulf. London: Hurst \& Company.

Karachaliou, R., \& Archakis, A. (2012). To re os diktis tou aprosdokitou. Analisi dedomenon apo synomiliakes afigisis ( $R e$ as an index of the unexpected. Data analysis from conversational narratives. Studies for the Greek Language, 32, 172-183. (in Greek).

Kirilova, M., \& Angouri, J. (2017). Communication practices and policies in workplace mobility. In S. Canagarajah (Ed.), The Routledge handbook of migration and language (pp. 558-576). New York: Routledge.

Knapp, M. L., Hall, J., \& Horgan, T. G. (2014). Nonverbal communication in human interaction (8th ed.). New York: Wadsworth Cengage Learning.

Lave, J., \& Wenger, E. (1991). Situated learning: Legitimate peripheral participation. New York: Cambridge University Press.

Lewis, H. (2000). Body language. A guide for professionals. New Delhi: Response Books.

Longva, A. N. (2005). Neither autocracy nor democracy but ethnocracy: Citizens, expatriates, and the sociopolitical system in Kuwait. In P. Dresch \& J. Piscatori (Eds.), Monarchies and nations: Globalization and identity in the Arab States of the Gulf (pp. 114-135). London: I. B. Tauris.

Lønsmann, D., \& Kraft, K. (2017). Language in blue-collar workplaces. In B. Vine (Ed.), The Routledge handbook of language in the workplace (pp. 138-149). New York: Routledge.

Lorente, B. P. (2017). Scripts of servitude: Language, labor migration and transnational domestic work. Bristol: Multilingual Matters.

Makoni, S. (2016). Romanticizing differences and managing diversities: A perspective on harmonization, language policy, and planning. Language Policy, 15(3), 223-234. https://doi.org/10.1007/s1099 3-015-9375-x.

McCarty, T. (2011). Entry into conversation. Introducing ethnography and language policy. In T. McCarty (Ed.), Ethnography and language policy (pp. 1-28). London: Routledge.

Nagy, S. (1998). This time I think I will try a Filipina: Global and local influences on relations between foreign household workers and their employers in Doha, Qatar. City and Society Annual Review, 20(1), 83-103. https://doi.org/10.1525/city.1998.10.1.83.

Neale, E. (2017). Qatar: Protecting the human rights of migrant workers. Available under https://www. sedexglobal.com/qatar-protecting-the-human-rights-of-migrant-workers. Accessed 05 November 2018. 
Osella, F., \& Osella, C. (2008). I'm Gulf: The production of cosmopolitanism in Kozhikode, Karala, India. In E. Simpson \& K. Kress (Eds.), Struggling with history: Islam and cosmopolitanism in the Western Indian Ocean (pp. 323-355). New York: Columbia University Press.

Osella, F., \& Osella, C. (2012). Migration, networks and connectedness across the Indian Ocean. In M. Kamrava \& Z. Babar (Eds.), Migrant labor in the Persian Gulf (pp. 105-136). London: Hurst \& Company.

Pennycook, A. (2012). Language and mobility. Unexpected places. Bristol: Multilingual Matters.

Pennycook, A., \& Otsuji, E. (2014). Metrolingual multitasking and spatial repertoires: 'Pizza mo two minutes coming'. Journal of Sociolinguistics, 18(2), 161-184. https://doi.org/10.1111/josl.12079.

Pennycook, A., \& Otsuji, E. (2015). Metrolingualism: Language in the city. London: Routledge.

Pennycook, A., \& Otsuji, E. (2017). Fish, phone cards and semiotic assemblages in two Bangladeshi shops in Sydney and Tokyo. Social Semiotics, 27(4), 434-450. https://doi.org/10.1080/10350 330.2017.1334391.

Phillipson, R. (2017). Myths and realities of 'global' English. Language Policy, 16(3), 313-331. https:// doi.org/10.1007/s10993-016-9409-z.

Pietikäinen, S., Jaffe, A., Kelly-Holmes, H., \& Coupland, N. (2016). Sociolinguistics from the periphery: Small languages in new circumstances. Cambridge: Cambridge University Press.

Prinsloo, M. (2017). Spatiotemporal scales and the study of mobility. In S. Canagarajah (Ed.), The Routledge handbook of migration and language (pp. 364-380). New York: Routledge.

Rossman, G. B., \& Rallis, S. F. (2003). Learning in the field: An introduction to qualitative research. London: Sage.

Rymes, B. (2014). Communicating beyond language. Everyday encounters with diversity. London: Routledge.

Sallabank, J. (2010). Prestige from the bottom up: A review of language planning in Guernsey. Current Issues in Language Planning, 6(1), 44-63. https://doi.org/10.1080/14664200508668272.

Seow, L. (2017). Cultureshock! India: A survival guide to customs and etiquette. Singapore: Marshall Cavendish Editions.

Shohamy, E. G. (2006). Language policy: hidden agendas and new approaches. London: Routledge.

Storti, C. (2015). Speaking of India. Bridging the communication gap when working with Indians (Revised ed.). Boston: Intercultural Press.

Theodoropoulou, I. (2015). Sociolinguistic anatomy of mobility: Evidence from Qatar. Language \& Communication, 40, 52-66. https://doi.org/10.1016/j.langcom.2014.12.010.

Theodoropoulou, I. (forthcoming). Semioscaping eutopia: Constructing Qatar as a place in Qatar Airways advertisements. In S. Chris, Q. Williams \& A. Peck (Eds.), Visceral landscapes special issue. Sociolinguistic studies (Vol. 19, Issue No. 1)

Theodoropoulou, I., \& Alos, J. (2018). With Julieta Alos. "Expect amazing!”: Branding Qatar as a sports tourism destination. Visual Communication. https://doi.org/10.1177/1470357218775005.

Vigouroux, C. (2017). Rethinking (un)skilled migrants. Whose skills, what skills, for what, and for whom? In S. Canagarajah (Ed.), The Routledge handbook of migration and language (pp. 312-329). New York: Routledge.

Vora, N. (2013). Impossible citizens. Dubai's Indian Diaspora. Durham: Duke University Press.

Warhol, L. (2012). Creating official language policy from local practice: The example of the Native American Languages Act 1990/1992. Language Policy, 11, 235-252. https://doi.org/10.1007/s1099 3-012-9248-5.

Watson, S. (2009). Brief encounters of an unpredictable kind: Everyday multiculturalism in two London street markets. In A. Wise \& S. Velayutham (Eds.), Everyday multiculturalism (pp. 125-139). Houndmills: Palgrave Macmillan.

Wilce, J. M. (2009). Language and emotion. New York: Cambridge University Press.

Publisher's Note Springer Nature remains neutral with regard to jurisdictional claims in published maps and institutional affiliations.

Irene Theodoropoulou is Associate Professor of Sociolinguistics at Qatar University and Associate of King's College London (AKC), from which she obtained her Ph.D. in Sociolinguistics. Her current 
research interests lie at the intersection of sociolinguistics, intercultural communication and discourse analysis with social media, advertisement and politics. Her geographical areas of interest include primarily Greece and the State of Qatar. She is the author of Sociolinguistics of Style and Social Class in Contemporary Athens (Benjamins, 2014), and her most recently published research appears in Journal of Arabian Studies, Discourse \& Society, Visual Communication, and Discourse, Context and Media.

\section{Affiliations}

\section{Irene Theodoropoulou ${ }^{1}$}

$\triangle \quad$ Irene Theodoropoulou irene.theodoropoulou@qu.edu.qa https://qu.academia.edu/IreneTheodoropoulou

1 Department of English Literature and Linguistics, Location: C04, Office 134, College of Arts and Sciences, Qatar University, P.O. Box 2713, Doha, Qatar 